\title{
Strategic Lessons to Emerge from an Analysis of Selected Flower Export Nations ${ }^{1}$.
}

\begin{abstract}
An examination of the flower export industries in the Netherlands, Colombia, Israel and Australia suggests that physical resource endowments are a major factor in the evolution of flower exports. However, without an appropriate investment in infrastructure and government support, such resources are seldom fully exploited. While preferential market access is most advantageous, the key success factor is the development of a fully integrated supply chain. Success is also more likely where flower producers have an export culture.
\end{abstract}

\section{Introduction}

The world trade in floricultural products is estimated to be worth US\$31 billion per annum and to be growing at an annual rate of 6-9\% (de Groot 1998). The Netherlands has the largest share of the world market, exporting over $59 \%$ of the cut flowers traded worldwide. Colombia is the second largest exporter, with a $10 \%$ share of the cut flower market, followed by Italy (6\%), Israel (4\%), Spain (2\%) and Kenya (1\%). Other countries not otherwise identified contribute a further 18\% (Flower Council of Holland 1998).

A number of factors are believed to be responsible for the growth of floricultural exports. On the demand side, the consumption of cut flowers worldwide has risen by $11 \%$ since 1985 (Rabobank 1992). The world's most wealthy countries (the USA, Germany and Japan) are the largest consumers. Cut flowers are traded all over the world, although the importance of domestic production is generally declining while imports are increasing. Worldwide, imports of flowers have increased $17 \%$ since 1985 . Europe is the largest importer (75\%) and Germany the world's largest import market (30\% of world imports)(de Groot 1998).

Worldwide, the area of flowers cultivated is believed to have increased by $13 \%$ since 1985 (Rabobank 1992). Over 25\% of the production is in Japan; the USA, Mexico, Italy and the Netherlands contribute $10 \%$ each. Currently, it is estimated that some 60,000 hectares are utilised worldwide for the production of cut flowers (de Groot 1998).

As the expansion in production (13\%) has exceeded the growth in demand (11\%), average prices are declining (AIPH 1996). Hence, in order to remain internationally competitive, both existing and emerging flower export nations are being forced to give increasing attention to the identification and development of those factors that will enhance and strengthen their competitive position.

In seeking to gain a better understanding of the international flower trade, this study sought to identify those variables that are the most influential in establishing and sustaining a competitive position in the international cut flower market.

\footnotetext{
${ }^{1}$ Batt, Peter J. (2000), Strategic Lessons to Emerge from an Analysis of Selected Flower Export Nations, Journal of International Food and Agribusiness Marketing, Vol 11(3), 41-73.
} 


\section{Theoretical foundation}

The theory of comparative advantage, as proposed by Ricardo in 1817 and refined by Ohlin and Heckscher in 1933, suggests that a country will export those goods that use most intensely, that country's most abundant factors of production (Root 1984). While factor theory might in part explain the growing success of flower exports from such countries as Colombia, Ecuador, Kenya and Zimbabwe, all of which, to varying degrees, are generally well endowed with the basic factors of production, the Heckscher and Ohlin theorem assumes that the factors of production are homogeneous. Such is, however, inappropriate.

Agriculture is one of the few industries that use land as an essential input in the production function (Timmer 1988). However, there is considerable variation in the natural attributes of land including its fertility, topographic features, insolation, rainfall, altitude and latitude that affect both its potential productivity and its substitutability. Furthermore, no country anywhere in the world can claim to have an absolutely constant year round climate. Variations in the climate cause agricultural production to follow distinct seasonal patterns, although with appropriate capital investment, seasonality is neither fixed or rigid. However, it is generally accepted that it is cheaper to let nature provide the majority of the essential inputs for production rather than to manipulate the environment. Seasonality not only influences the price, the quantity and quality of produce offered for sale but consumers may also respond to seasonal and other marketing stimuli. Seasonality of demand, supply and related prices are one of the more important aspects of the international trade in cut flowers (Ganitsky 1986).

In order to capture nature's endowments, farms are generally widespread (Timmer 1988). However, if any farm outputs are to leave the farm for consumption by others, or if inputs, such as seeds, fertilisers or pesticides, are to be used to raise output, transportation becomes critical. Appropriate distribution management is an essential prerequisite for the development of a sustainable export industry (Offiongodon 1988). Without an efficient distribution system, a nation is limited to local economies, spot shortages and wastage of surplus production.

Mentzer and Samli (1981) recognise that economic development cannot progress without well developed systems of transport, storage, communication and marketing. Any improvement in transport that lowers price or improvements in technology that facilitate the rapid movement of goods under favourable conditions, may convert domestic goods into international commodities, especially where there is strong foreign demand (Root 1984). The rapid increase in the geographic distribution of fresh flower exports can be attributed to the advent of low cost and reliable air freight services and the diffusion of improved flower growing techniques (Ganitsky 1986).

However, Porter (1990) suggests that sustainable competitive advantage seldom arises from a country's natural resource endowments, but rather from the capacity of its industries to innovate and upgrade. Innovation is derived from conceiving new ways to conduct activities, employ new procedures, new technologies or different inputs. Innovation shifts competitive advantage when rivals either fail to perceive the new way of competing, or are unwilling or unable to respond. Early movers gain advantages by being the first to achieve economies of scale and cost reductions through cumulative learning, establishing brand names and customer relationships, seeking control of distribution channels and the best sources of raw materials and inputs.

Once a firm achieves competitive advantage, it can sustain it only through making continuous product and process improvements (Porter 1990). However, creating a more sustainable 
competitive advantage often means that the firm must make its existing advantage obsolete. Nevertheless, benefits may arise from the economies of scale, reduced costs, improved product quality and improved customer satisfaction.

In determining and sustaining competitive advantage, Porter (1990) finds it necessary to distinguish between the basic factors of production which he describes as physical resources; land, climate and location; unskilled and semi-skilled labour and debt capital, and, the more advanced factors of production which include highly skilled labour; research institutions; transportation and communication systems and infrastructure.

While the basic factors of production may be passively inherited and require only modest investment to develop their potential, such factors are becoming increasingly less important to national competitive advantage, for their importance has been undermined by either their diminished necessity or their widening availability (Porter 1990). Porter proposes that the advanced factors of production are more important in building sustainable competitive advantage, for these factors are less abundant and their development requires large and sustained investments in both human and physical capital. Nations succeed in those industries where they are particularly good at factor creation. However, competitive advantage can also arise from selective factor disadvantage. Firms who innovate to offset selective disadvantage build upon local strength and develop competitive advantages that can be sustained longer and which may support higher prices. Porter considers the development of the Dutch cut flower industry to be an outstanding example of the influence of selective factor disadvantage. The Netherlands is the world leader in floricultural exports despite its cold, grey climate. This selective disadvantage has led to an innovation in greenhouse growing techniques that have created sustainable competitive advantages for the industry. Dutch innovation proceeded in a direction that took advantage of a large supply of natural gas and it allowed the Dutch industry to achieve differentiation based on freshness, quality and variety.

To innovate, firms must have access to people with appropriate skills and active domestic rivals who create the pressure to innovate (Porter 1990). Local rivals push each other to lower costs, improve quality and service and create new products and processes. Strong domestic rivalry also eliminates those types of competitive advantage that come from simply being in a particular nation. Firms are forced to move beyond such advantages as factor costs, access to the market, costs to foreign competitors who may wish to import and government protection. Ironically, it is also vigorous domestic competition that ultimately forces domestic firms to pursue the global market. Encouraging competition in domestic markets not only facilitates and improves market access (Ganitsky 1989), but enhances and develops the technical skills of producers (Timmer 1988).

Firms gain competitive advantage where domestic consumers are more sophisticated and demanding buyers (Porter 1990). Competitive forces require firms to meet higher standards of quality, features and service. While the fundamental product attributes generally reflect home market needs, exposure to the broadest range of different market segments provides a wider experience base which may prove useful in entering foreign markets. Large domestic markets may also lead to competitive advantage where there are economies of scale and learning, substantial research and development requirements and high levels of uncertainty.

The final determinant of national advantage is the presence of related and supporting industries (Porter 1990). Internationally competitive home-based suppliers create advantages in downstream industries in several ways; they deliver the most cost effective inputs, rapidly and 
efficiently, but perhaps more importantly, when suppliers and customers are located close to one another, they can take advantage of short lines of communication, the quick and constant flow of information and the ongoing exchange of ideas. Firms have the opportunity to influence their suppliers technical efforts and can act as test sites for research and development, accelerating the pace of innovation.

The importance and uniqueness of agriculture often encourages government involvement in both production and marketing. Government intervention in the market can be controversial, but it is usually justified by the concern that markets and prices do not necessarily allocate resources in the best way to satisfy the needs of individuals and society (Kohls and Uhl 1990). Those who oppose government intervention describe the inhibiting effects on innovation, efficiency and competition (Porter 1990), or the costs of regulation which are ultimately borne by the producer or the consumer (Shepherd and Futrell 1982). Too much interference can stifle the profit seeking and independence of decision making that is vital in a decentralised free enterprise system, or direct firms into less sustainable, price sensitive market segments (Porter 1990). Conversely, those who support government intervention, emphasise the need to harness private profit making efforts in the public interest and to protect both the producers and the consumer from anti-competitive market practices (Kohls and Uhl 1990).

There is a tendency for society to associate regulations with restrictions, but government policies can also be permissive. The legislation under which wholesale markets are established, quality and maturity standards implemented and maintained and market information systems operate, are a benefit to the free marketing system (Kohls and Uhl 1990). Government policies will also have both a direct and indirect influence on the development of international markets (Seringhaus and Rosson 1990). Indirect programs focus on production and supply, seeking to increase productivity through encouraging research and development, technology and innovation, establishing appropriate infrastructure to facilitate more efficient transportation and handling, manpower development and regional development, and, fiscal policies that seek to encourage production by providing financial and investment incentives, taxation shelters and stimulate demand. Government must also provide incentives for individual firms to overcome motivational, informational and operational barriers which might otherwise prevent export. In addition to providing the basic infrastructure and institutional framework, Government may also have substantial power over the control and ownership of banking, foreign exchange and credit and foreign trade (Evans 1989). The state may regulate patterns of private investment, the choice and application of technology and exercise import controls (Lewis 1988). Government may also impose quantitative restrictions in an effort to keep international payments in line with export receipts. However, if protection is the only source of national competitive advantage, Government policy will ultimately fail (Porter 1990; Seringhaus and Rosson 1990).

To sustain competitive advantage, Government must design appropriate economic policies that create the necessity for innovation by way of incentives and regulations (Poutsma et al 1987). Government cannot create competitive industries; quite to the contrary, Governments have been generally most unsuccessful in managing firms and responding to market forces. Consequently, the role of Government must be to stimulate investment; to encourage the introduction of more sophisticated technology, assist firms to penetrate more advanced market segments, encourage competition and upgrade the demand conditions (Porter 1990). 
The importance of government in recognizing and supporting the economic development of primary industry through appropriate export incentive programs has been discussed by Huszagh and Huszagh (1987), Nichols et al (1988), Offiongodon (1988) and Ganitsky (1989).

\section{Methodology}

Using Porter's (1990) model of national competitive advantage, an analytical framework was established to enable a qualitative comparison to be made between the four countries chosen for the study. A score of 1 indicated that the variable was either very poor or very expensive, and a score of 6 indicated that the variable was either very good or inexpensive. An overall assessment was calculated by dividing the sum of the scores by the maximum possible score. Aggregate scores were also calculated for the physical (basic) factors, economic (advanced) factors, demand conditions, firm's structure and rivalry, related and supporting industries and government. Performance was rated against the value of flower exports.

Individual scores for each of the variables evaluated was based wherever possible on existing literature. However, like most other studies in this area including Ganitsky (1986), Rabobank (1992) and de Groot (1998), personal judgement was the major mechanism for assigning the respective scores. In this regard, relying on the literature alone is inherently dangerous, and thus, to ensure a more objective evaluation of the chosen variables, personal visits were made to each of the countries selected for the study. Extensive discussions were conducted with the respective flower export councils/associations, research organisations, flower growers, exporters and importers.

The Netherlands was chosen for the study as the Dutch are the world leaders in floricultural production and marketing. The strategies employed by the Dutch are suggested as being the most appropriate for overcoming selective factor disadvantage and for maintaining and consolidating market share (Porter 1990).

Colombia is the world's second largest exporter of cut flowers. With a mature flower export industry worth in excess of US\$555 million (Colombian Flowers 1999), Colombia has capitalised on its natural resource endowments and comparative advantages so that today, Colombia dominates the flower import market in the USA and is becoming increasingly aggressive in both Europe and Japan.

Israel is the world's fourth largest exporter of cut flowers. While counter seasonality and proximity to the world's major market has provided competitive advantage, they too have had to overcome significant factor disadvantages.

Australia is a relatively new entrant in the world flower export industry. Australia would seem to have the potential to become one of the world's major flower producers, for Australia is a vast country with a diversity of climates from temperate to tropical and a unique range of wild flowers. However, Australian exports of flowers amount to less than one percent of aggregate world production and in contrast with several other southern hemisphere flower producers, exports represent less than $10 \%$ of total production (RIRDC 1997).

Ganitsky (1986), in his evaluation of the Colombian and Israeli flower industries, identified 21 relevant and important factors, classifying them under three broad headings as domestic, international and internal factors. Ganitsky chose a 4 character rating scale, ranging from $++(a$ major strength) to -- (a major weakness). 
The Rabobank (1992), in their evaluation of the Dutch flower export industry, used Porter's (1990) model to build a similar framework to assess the Dutch, Colombian, Israeli, Italian and Spanish flower export industries. Using 11 variables, a rating scale of 1 (very poor and expensive) to 4 (very good and cheap) was used to enable a meaningful comparison to be made.

De Groot (1998) also used Porter's (1990) framework to make a comparison between the Dutch flower export industry and the competition from both Latin America and Africa. Like Rabobank (1992), the Agricultural Economics Research Institute used the same 11 variables and a similar rating score of 1 to 4 .

\section{The Dutch flower export industry}

Commercial flower growing in Holland dates back to the early part of the last century. Due to diminishing market returns, strawberry and fruit growers in Aaslmeer, diversified into the cultivation of flowers and plants. However, the harsh and unpredictable climate adversely affected both yields and quality and growers were forced to consider protected cropping. In 1871, the first heated glasshouse was built for the cultivation of pelagoniums. In 1911, the first Dutch auction for cut flowers was established at Aalsmeer and as the production of cut flowers increased in the Westland, a second flower auction was opened in 1923 (Flower Council of Holland 1991). Today, some 5,700 hectares are devoted to cut flower production in Holland, with some 3,600 hectares under protected cropping (RIRDC 1997a).

While the soils are very fertile, the climate is cool and temperate. Although close proximity to the ocean has a moderating influence, the climate is unpredictable. However, the Netherlands has Europe's largest supply of natural gas and it is that gas that provides the energy to heat the greenhouses (Lanning 1986). Even so, the fuel crisis of the 1970's, forced Dutch growers to identify ways of reducing costs and conserving energy. Major adjustments occurred in the greenhouse industry to increase the height of the structures and improve light transmission, for a $1 \%$ increase in light is equivalent to a $1 \%$ increase in yield. Coupled with improved automation and control of the greenhouse environment, and, the breeding and cultivation of plants that required less energy, the Dutch flower industry was very rapidly able to accommodate the changes.

However, more recently, the Dutch flower industry is facing increasing competition from low cost imports. Cut flower prices are declining, forcing producers to seek alternative means to further reduce costs and to increase productivity. Increases in productivity and economies of scale are more easily obtained in larger firms, hence, as the industry consolidates, farms are getting larger (Hamrick 1996). With the increasing costs of labour, flower producers are also giving much greater consideration towards mechanisation and automation of the production process.

The majority of the cut flowers produced in the Netherlands (92\%) are sold through the Dutch auction system (VBN 1995). There are seven auctions; the two largest of which (the VBA and Westland), account for $82 \%$ of the trade in cut flowers and pot plants.

The auction plays a central part in the distribution of Dutch flowers. It is the point where both supply and demand are concentrated and where prices are established; the auction organises the distribution of the product to both domestic and export markets; and the auction conducts a limited amount of market research and product research (Rabobank 1992). 
One of the principle advantages of the auction system is that growers do not encounter each other as direct competitors. Consequently, a sense of comradeship evolves and growers tend to regard one another as colleagues. The industry is cooperative in nature (Rabobank 1992).

To their mutual advantage, Dutch growers have sought to collect levies to finance promotion and research. Under the legislative powers granted to the Ornamental Products Commodity Board, growers are required to pay an annual levy on the area of flowers cultivated. An additional levy of $0.45 \%$ is collected from the proceeds of auction returns. This figure is matched by a contribution of some $0.35 \%$ from the flower wholesale trade. Collectively, $63 \%$ of the levies are used to fund the activities of the Flower Council of Holland in promoting the sale of Dutch flowers both domestically and abroad. The balance (37\%) is used to support research and development programs to improve productivity per unit area.

However, a major disadvantage of the auction is that growers have little direct contact with end users, and, as a result, information from the market may not always reach the producers (Rabobank 1992). There is also an increasing realisation that wholesale demand has changed; there are fewer, more powerful buyers, who, being able to exert considerable downward pressure on price, are encouraging greater consolidation and integration of the supply chain (Hamrick 1996). Growers are developing alliances with one another, with exporters and directly with the retail chains.

The main flower crops cultivated in the Netherlands are roses, chrysanthemum and the bulb crops (RIRDC 1997a). While the wholesale value of roses has remained relatively steady, the value of chrysanthemums and carnations has steadily declined, indicative of the increasing volume of flowers imported. Imported flowers currently constitute about $15 \%$ of the flower auction turnover.

Israel is the main supplier of roses to the Dutch flower market, but with the emergence of aggressive new flower producers in Zimbabwe and Morocco, Israel's share of the Dutch market has progressively declined. Nevertheless, Israel continues to dominate the market and in terms of total flower imports, Israel is the major supplier.

The Netherlands is the most dominant force in world flower trade. The value of Dutch flower exports exceeded US\$2,860 million in 1995 (AIPH 1996). The majority of Dutch flower exports (82\%) are consigned to neighbouring countries in the European Union. Germany is the most important market for Dutch flower exports, accepting over $45 \%$ of exports. Roses and chrysanthemums are the two most important Dutch flower exports, although collectively, the flowering bulb crops (freesia, gladioli, lilium, iris, narcissus, tulip and nerines) make the biggest contribution to export sales (23\%).

The Netherlands is the third largest exporter of agricultural products in the world. While the majority of farms are small family enterprises, a number of factors have been important in enabling Holland to achieve international recognition. These factors include systematic land consolidation, capital intensive technical applications, high quality propagation material, high training levels and a close association between research and practice. Dutch farmers are continuously improving their product quality by the integration of quality management concepts from the farm gate to the consumer. Government regulations drawn up by the trade and industry itself, established the control mechanisms (Holland Agriculture 1989). 
Whereas in the past, the consumer was more concerned with the quantity of food available, today, the consumer prefers a simpler, cleaner, healthier way of eating. To meet the challenge, Dutch agriculture is looking towards technology to reduce the dependence on pesticides and fertilisers. The Dutch government's NEP-Plus plan calls for a $70-90 \%$ reduction in pollution levels by the turn of the century. By the Year 2000, the Dutch flower industry is required to be growing in closed production systems so as to reduce the contamination of water supplies.

Although the per capita consumption of flowers in Holland is amongst the highest in the world (\$US35), the domestic flower market in the Netherlands is relatively small. On average, 61\% of households purchase flowers at least once per quarter (Rabobank 1992). Flowers are mostly purchased as gifts (57\%), or for the buyer's own use (39\%), while the funeral market represents only $4 \%$. However, the distribution network is very extensive, for there is one point of purchase per 2,300 inhabitants.

\section{The Colombian flower export industry}

Colombia is the world's second largest exporter of fresh cut flowers, with exports currently valued in excess of US\$555 million (Colombian Flowers 1999). Colombia is, however, a relatively new entrant into the world flower market. Intensive flower production began in Colombia in the mid 1960's, yet within only three decades, Colombian flowers have captured $10 \%$ of the world market and two-thirds of the flowers sold in the US are Colombian imports.

The spectacular growth of Colombian flower exports has been attributed to several factors including; (i) Colombia's geographic position, which climatically, provides an almost ideal growing environment for the production of temperate flowers; (ii) low costs of production including; low capital costs of greenhouse structures and maintenance; low costs of labour; and, low cost airfreight to the USA; (iii) relative proximity to the USA market; (iv) substantial Government support for the flower industry; and, (v) a favourable exchange rate.

At an altitude of 2,600 m, the vast, fertile, cool plateau surrounding Bogota is almost ideal for the year round production of cut flowers. High light intensity and near perfect day lengths achieve the desired balance between flower production and vegetative growth, and a diurnal and seasonal temperature range which seldom falls below $10^{\circ} \mathrm{C}$ or rises above $20^{\circ} \mathrm{C}$, infers that only modest polyvinyl greenhouses are required to protect the crop from the weather. Currently, some 450 farms covering 4,500 hectares are producing cut flowers, primarily for export (95\%)(Pizano 1997).

Carnations are the major flower crop grown in Colombia (36\%). Colombian carnations are competitive world wide and are generally well accepted, for Colombian carnations are synonymous with quality. However, over recent years, the value of carnation exports have declined as Colombian flower growers have sought to diversify and to improve their product range. While roses now comprise almost 32\% of exports, the fastest growing sector in the Colombian flower export industry is the production of "other flowers". Today, Colombia exports more than 50 different types of flowers (Colombian Flowers 1999).

The main market for Colombian flowers is the mainland USA (79\%), where Colombian flower imports are valued at more than US\$370 million (Colombian Flowers 1999). On a daily basis, some 15,000-20,000 cartons of flowers arrive and are processed through Miami International Airport (Luxner 1997). 
The distribution system established by Colombian flower exporters and their US partners is one of the real strengths of the Colombian flower export industry. Flowers can be harvested in Colombia in the early morning, packed and despatched by noon to arrive in Miami (after a three hour flight) and be in the importers' coolstores by late afternoon. Flowers arrive in near perfect condition, having been force air cooled prior to despatch and transported to and from the airport in air conditioned trucks. Nevertheless, on arrival in Miami, rigid quality control is undertaken by the importers to check the box contents, for most product imported into the USA is forward sold.

However, in more recent times, Colombia has faced increasing competition from other Latin American countries for a share of the North American flower import market. Despite vigorous efforts to protect their market share by diversification, new and more aggressive competitors from Mexico, Costa Rica and Ecuador threaten to erode Colombia's traditional dominance. These countries draw much of their competitive advantage from being closer to the market and with additional elevation (with particular reference to Ecuador), produce a flower said by many USA flower importers to be superior to the Colombian product. With inflation in excess of $20 \%$ per annum, labour exceeding $55 \%$ of production costs and a further $17 \%$ devaluation of the Colombian peso, the costs of flower production in Colombia are increasing while real returns are decreasing (Aimone 1998). Furthermore, the failure of the government to follow through on promised counter-narcotic activities threatens to erode preferential access for Colombian flowers into the USA (Luxner 1997) and retrospective allegations of dumping continue to undermine confidence in the Colombian flower export industry.

Up until 1970, Colombian flower exporters were solving their own problems independently, but with the US imposing countervailing duties on Colombian flower imports, the Association of Cut Flower Exporters (Ascolflores) was founded (Ganitsky 1986). Its primary purpose was to advance the common interests of the industry. Members shared technical, financial and administrative resources. For and on behalf of its members, Ascolflores negotiated freight rates with the airlines and was responsible for the formation of a cooling and handling service company in Miami. Today, Ascolflores is very active in promoting and defending Colombian flowers from alleged dumping, violating workers rights and damaging the environment. The Association also provides research funding, continuing education, social welfare programs and information to industry (Pizano 1997). Colombian flower growers recognise that, in order to enhance sales, the US market requires substantial promotion and retailer education. Most of the leading wholesalers conduct training seminars to advise on in-store presentation, post-harvest care and handling and the proper names and origins of the various and different flower types. However, generic promotion is also undertaken by the Colombian Flower Council, generally in conjunction with the Society of American Florists (SAF).

In promoting the development of the flower export industry, the Government of Colombia offered low interest loans, direct taxation benefits and provided significant reductions in import duties for materials used in the production process. But, in the late 1970's, US flower producers alleged that Colombian flower growers were "dumping" on the US market at below home market prices and were, because of government taxation and investment incentives, being subsidized by the Colombian Government. In 1974, the government reduced the value of the tax exemption certificates from $15 \%$ to $0.1 \%$ for flower exports to the US. Even so, under a system whereby the US government compares monthly weighted average prices of US sales with those of a third country or a constructed value for a random sample of exports, duties of from 0 to $83.97 \%$ have been brought against several Colombian flower exporters. 
Today, the Colombian Government actively supports the flower industry through a program of modernization, encouraging the development of infrastructure to enhance the efficiency of those industries that can demonstrate a comparative advantage. In this respect, the Government seeks to encourage research and development by the private sector and to provide protection for intellectual property. In trade and investment, the Government is pursuing a policy of gradual liberalization of imports, redesigning the main instruments of export subsidies and facilitating the entry of foreign capital (Colombia Today 1990). Medium and long term loans and equity grants assist enterprises to acquire machinery and equipment, initiate the construction of new facilities and enable firms to undertake technical studies of production, marketing and administration and environmental impact studies.

\section{The Israeli flower export industry}

Since it was first proclaimed on May 14, 1948, the independent state of Israel has witnessed unprecedented economic growth. What makes it all the more outstanding, is that since gaining independence, Israel has been involved in prolonged conflict with its Arab neighbours; it has absorbed over two million Jewish migrants and refugees; and it was first necessary to rebuild the nation's infrastructure. The main factors that have contributed to the economic growth in Israel include the steady rise in population; a large labour force; the recruitment of large amounts of foreign capital; and, a steady rise in productivity and innovation (Karmon 1971).

In view of the country's high quality labour force and absence of most raw materials, industry has concentrated on manufactured products with high added value. However, agriculture, while it comprises less than $4 \%$ of gross domestic product, is afforded special consideration (Central Bureau of Statistics 1999). Within Israel, there is a shortage of arable land and water, hence the government is most enthusiastic towards those industries that minimise the use of scarce resources and from which maximum productivity can be achieved. Few agricultural industries can approach the productivity attained from the cultivation of cut flower crops. The Government has actively encouraged the development of the flower export industry through offering a $40 \%$ cash grant on the initial investment in infrastructure (greenhouses and irrigation systems, packing sheds and cool stores) and, through the traditional cooperative system, the payment of settlement allowances for migrants in the occupied territories. Furthermore, it has been suggested that authorities failed to enforce statutory regulations which demanded the payment of minimum wages for, in rural Israel, there is a very large "volunteer" work force, many of whom do not draw a wage or are paid a figure well below the accepted minimum rate (Karmon 1971).

Israeli agriculture has attained a level of technical efficiency rivalling that found in the most developed countries. The shortage of water has made it necessary to develop systems for its efficient application and use and the high capital cost of installing the central artery from Lake Kinneret made it necessary to plan utilization of supply. For many agricultural products, production quotas are maintained to minimise surplus production.

Temperatures are generally favourable for agriculture and even in the cool season, most parts of the country reach temperatures above $10^{\circ} \mathrm{C}$; the critical point for plant growth. However, for the production of intensive cut flower crops, protection is essential to minimise the effects of extreme day temperatures and low humidity (sharav) and to counter very low night temperatures. As most greenhouses are relatively simple polyvinyl structures, often without supplementary heating, flowering may be delayed by unfavourable environmental conditions. 
Currently, Israeli flower exports are worth US\$224 million (Central Bureau Statistics 1999). Europe has traditionally been the major market for Israeli flower exports. The majority of flowers produced in Israel (88\%) are shipped during the winter months (October to May). When Israel first entered the flower export market in the late 1950's, it produced primarily gladoli, but by the mid 1980's, spray carnations, roses and gypsophila were the major crops. However, with increasing competition from Africa and South America, the area of traditional flower crops has declined and there is a growing emphasis on the production of summer flowers and foliage for the European winter. Currently, with some 1,800-2,000 hectares of cut flowers cultivated for the export market (Hamrick 1995), "other flower" crops comprise over $74 \%$ of exports (Olentine 1996). While the area of cut flowers grown for export has increased, the number of flower growers are declining and average property sizes are increasing.

Although once the primary mechanism for the sale and distribution of Israeli cut flowers, sales through Agrexco are gradually declining as the majority of flowers entering Europe are sold through the Dutch and German flower auctions. Agrexco, the Agricultural Export Company is a partnership between the Israeli Government (50\%) and growers, represented by each of their production and marketing Boards. There are four boards (citrus, flowers, fruit and vegetables).

The Production and Marketing Board for Ornamental Plants (the Flower Board) was established in 1961. In 1976, legislation enabled the Flower Board to act as a statutory marketing authority. The Flower Board was granted broad powers to administer supervise and plan, the production and marketing of flowers, bulbs and ornamental plants. The Flower Board, however, does not have exclusive rights to the marketing of ornamental products from Israel. At the time of its establishment those growers who were already shipping flowers and ornamental plants were granted export licences. Agrexco itself has an export license and is, in effect, sub-contracted by the Flower Board to collate, ship and distribute flowers on its behalf.

The Flower Board operates through eight regional packing houses and five designated transit stations, collecting the flowers from the growers, packing the flowers and transporting flowers to the central warehouse at Ben Gurion airport (Tel Aviv). Under the Act, flower growers are required to submit a Contract of Delivery Intent, specifying the areas of flowers grown for export and their preferred method of sale. Growers may choose to sell either by auction or through Agrexco, but they cannot change their method of sale once the export season begins.

In recent years, the quantities of flowers shipped under the Agrexco label (Carmel) has declined to less than $30 \%$. The greatest difficulty experienced by growers selling through Carmel is their anonymity; the subsequent lack of any market feedback, quality standards which do not necessarily favour the better growers and general opposition to the concept of price pooling. Better growers believe that the system is unable to adequately differentiate between the quality of flowers produced and that the prices achieved do not justify the additional costs of growing a superior product. However, although difficult to substantiate, as Carmel tends to work with the boutique florists, they seem able to command a higher price. Carmel may also purchase and resell additional and complimentary products in order to meet customer requests and needs. Furthermore, unlike the auctions where all products consigned to the market is sold, Carmel can, in the short term, hold back surplus products in an effort to smooth supply. However, in a situation where supply exceeds demand, Carmel may be forced to lower the price in an effort to move excess product, or resort itself, to consigning flowers to the auction market.

Through their sales offices in Europe, sales representatives from Carmel estimate the strength of the market, the volumes of flowers they can sell and the prices they can achieve. Market 
information is relayed to the main Agrexco sales office, where it is collated and compared to the quantities of flowers processed that day and held in cool storage by each of the packing houses. Flowers are consigned to each market according to which offers the best price. Each packing house is then advised of the markets to which their products has been consigned.

Using the distribution system established, flowers leave Tel Aviv late afternoon to arrive in Cologne (Germany) some 3-4 hours later. The shipment is broken down and despatched by truck to destinations throughout Europe. A system of palletisation, used from the time flowers are despatched from the packing sheds and transit stations, ensures that cartons are handled rapidly and as little as possible.

While there are no statistics available on the domestic flower market in Israel, it is thought to be worth about US\$50 million a year (Rabobank 1992), or US\$22 per capita. Flower imports are virtually non existent, for the presence of import tariffs of $20 \%$ for EU countries and $160 \%$ for other countries effectively makes import unattractive, although substantial quantities of plant material are imported for growing out and subsequent re-export.

\section{The Australian flower export industry}

Australia is a vast country, which, with a diversity of climates (from temperate to tropical), a unique range of native and exotic flowers and a favourable location in the southern hemisphere, has the potential to supply markets in the northern hemisphere at a time of the year when demand is highest and production most difficult. However, Australian flower exports amount to less than $1 \%$ of aggregate world production, and, in contrast with several other southern hemisphere producers, including Kenya, New Zealand and Zimbabwe, exports represent less than $10 \%$ of total production.

In 1997/98, Australian flower exports were worth almost US\$18 million (FECA 1999). While the value of Australian flower exports have increased from less than US\$2 million in 1980/81, the flower export industry in several other countries have expanded at a much more rapid rate so that, in real terms, Australia's share of the world cut flower market is diminishing.

The Industry Commission (1993) believes that Australia has performed badly in both its traditional and emerging horticultural markets. Government believes that this is due to an uncoordinated approach to exports; the lack of market infrastructure; inadequate quality control; and, inadequate market research and promotion. It is perceived that most Australian growers give preference to the domestic market; most growers do not have an export culture; most operations are too small and their individual operations uncoordinated; labour is expensive; the cost of transportation is expensive; the value of the Australian dollar is too high; and, with other countries subsidising horticultural exports, Australian producers are finding it increasingly difficult to compete. RIRDC (1997) concluded that the most serious constraint to the expansion of Australian flower exports was air freight access, the high cost of air freight and lack of facilities. However, other serious impediments included fluctuations in the value of the Australian dollar, inconsistent quality, insufficient good quality product, declining prices in the world market, distance from the market and quarantine regulations, both in Australia and overseas.

In Australia, it is apparent that off-farm costs are significantly greater than on-farm costs. For fresh cut flowers, air freight represents the largest component of the off-farm cost. While the air freight industry was deregulated in October, 1987, flower exports remain dependent on 
scheduled passenger services, on which there is limited space, a limited number of flights and destinations and a lack of suitable storage facilities (Industry Commission 1993). However, these impediments are due to commercial factors rather than regulatory mechanisms, for in order to use the space available, flower exporters may have to pay more competitive freight rates for, at present, flowers are shipped primarily on a volumetric basis, rather than weight. Nevertheless, air freight rates from Australia are expensive, with costs ranging from US\$1.30-4.25 per kilogram. Furthermore, a modest 5\% reduction in the landed price is equivalent to a $15-20 \%$ reduction in farm gate returns, thus, only a slight movement in the exchange rate can make Australian flowers uncompetitive (NRCFM 1992).

Japan is the major market for Australian fresh and dried flowers (43\%)(FECA 1999). While Australian flowers enter Japan duty free, into the USA, there is an 8\% import duty and into the EU, import duties range from 15\% (November through May) to 20\% (June to October). With the exception of New Zealand, Australia is generally excluded from most regional trade development programs. While there are no import duties payable on cut flowers entering Australia, because of Australia's geographic isolation and relative freedom from exotic pests and diseases, all imported flowers entering Australia must be dipped in glyphosate to prevent their propagation. Such legislation is thought to have both shielded local producers from overseas competition and, in the past, to have restricted access to many new and improved plant varieties (Batt 1982).

Domestically, the Australian cut flower industry is believed to be worth some US\$185 million per annum (RIRDC 1997). With a population of around 17 million, such would suggest that per capita flower consumption in Australia was in the region of US\$9.50, which, by world standards, is rather low. The majority of cut flowers grown for the domestic market are the traditional flower crops (roses, carnations, chrysanthemums and the bulb crops). As there is a great diversity of climates between the states and flowers move relatively freely between the states, the majority of flower crops are cultivated under inexpensive and unsophisticated polyvinyl greenhouses. However, with the exception of cymbidium orchids, the majority of Australian flower exports are the native flowers and exotic proteaceae (93\%)(FECA 1999). Invariably, these crops are cultivated outdoors with minimal protection and although increasing quantities of native flowers are being cultivated, a substantial proportion of those exported are still harvested from natural bushland and managed farm lots.

It is widely accepted that flowers and foliage harvested from the wild are of an inferior quality and do irreparable damage to the reputation of Australian flower exports. However, bush picked flowers continue to make a significant contribution to Australian flower exports. For many species which have good potential in the market, the mechanisms influencing the ability of the plant to regenerate are not fully understood and despite repeated attempts, many species cannot be commercially propagated. The lack of knowledge of the flowering mechanisms and of crop management suppresses yield and for several species, commercial cultivation introduces pests and pathogens which, in natural stands, present little if any problem. In harvesting native flowers from the bush, there are fewer financial risks and no barriers to market entry. Finally, the lack of industry research and development funds is said to preclude both individuals and institutions from undertaking much of the exploratory work required to both commercialise and improve the native flora.

Flowers and foliage harvested from the wild are not only of an inferior quality, but the quantity of marketable flowers available are inconsistent and highly dependent upon both the frequency and intensity of rain and the occurrence of fire. Furthermore, in terms of exporting products to 
those countries with very stringent phytosanitary requirements (such as Japan), there is a higher degree of interception by Plant Quarantine officers and subsequently more frequent fumigation that further reduces quality and market prices. For many species such as Boronia, the flowering season is so concentrated that it is near impossible to maintain a continuous supply.

In July 1991, the Australian Horticultural Corporation introduced the Australian Horticultural Quality Certification Scheme. While the scheme sought to establish a formal mechanism for the recognition of production and processing systems, the flower export industry has yet to establish and implement any formal flower export standards.

Although the flower industry is represented by a number of organisations, no single group can claim to be truly representative (Wain 1992). The Australian Flower Growers Council (AFGC) was formed in 1985. Although it has one grower representative from each state, it has not sought representation from flower exporters, wholesalers or retailers. The AFGC seeks to assist flower growers through representation to Government to secure assistance with research and development and to promote the interests of flower growing. The Flower Export Council of Australia (FECA) was established in 1990 to strengthen the promotion and marketing of Australian flowers overseas, disseminate market research and address relevant industry problems. However, both organisations are funded by voluntary levies and experience would suggest that organising and obtaining funds from individuals is not only very expensive, but often impossible, if left to voluntary processes.

\section{Discussion}

In order for a meaningful comparison of the flower export industries in each of the four countries to be made, an aggregate table was prepared from the results of the competitive assessments (Table 1).

In terms of the physical resource endowments (land, water and climate), Colombia was the most endowed of the four countries studied. Australia was considered to be the second best, for the soils in Australia are not as fertile as those in Colombia nor as inexpensive, nor is the climate as conducive for optimal plant growth. While there is little difference between the climate in Israel and that in much of Australia, the calcareous nature of the soils in Israel present a major problem. Furthermore, in order to provide water to flower producers, it must be piped from Lake Kinneret, thus adding appreciably to the cost and imposing restrictions on its use. In the Netherlands, the low-lying nature of the land, its susceptibility to flooding and its high cost are considered a negative factor.

In considering the seasonality of supply, both Australia and Israel are in the best position to supply the markets in Europe, Japan or the USA at the time of the year when the supply of flowers is low and when the demand is highest. But whereas Europe is relative accessible to Israel, it is a great deal further for Australia. However, of the four study countries, Australia is the closest to Japan, the world's biggest market for cut flowers. In terms of their proximity to the European market, the Dutch are ideally placed, although they are somewhat more distant from the USA. Colombia, on the other hand, is very close to the USA, but more distant from the markets in Europe. 
Table 1. Aggregate Results of the Competitive Assessment of Flower Export Countries.

\begin{tabular}{|c|c|c|c|c|}
\hline & AUS & COL & ISR & NDL \\
\hline Export value (\$US million) & 17 & 556 & 224 & 2,280 \\
\hline Factor condition; Physical resource endowments & 0.62 & 0.90 & 0.67 & 0.55 \\
\hline Land & 5 & 6 & 3 & 4 \\
\hline Water & 5 & 6 & 1 & 4 \\
\hline Climate & 4 & 6 & 4 & 3 \\
\hline Seasonality & 6 & 4 & 6 & 3 \\
\hline Proximity to market & 2 & 5 & 5 & 6 \\
\hline Cost of labour & 2 & 6 & 5 & 1 \\
\hline Capital & 2 & 5 & 4 & 2 \\
\hline Economic development & 0.48 & 0.83 & 0.88 & 1.0 \\
\hline Economies of scale & 3 & 6 & 6 & 6 \\
\hline Range of product & 4 & 5 & 5 & 6 \\
\hline Transport & 2 & 6 & 6 & 6 \\
\hline Distribution channels & 2 & 6 & 5 & 6 \\
\hline Market promotion & 3 & 4 & 5 & 6 \\
\hline Quality control & 2 & 5 & 5 & 6 \\
\hline Technology & 4 & 3 & 5 & 6 \\
\hline Demand conditions in domestic market & 0.5 & 0.5 & 0.5 & 1.0 \\
\hline Related and supporting industries & 0.5 & 0.5 & 0.67 & 1.0 \\
\hline Firm structure and rivalry & 0.39 & 0.83 & 0.89 & 1.0 \\
\hline Organisational culture & 3 & 6 & 6 & 6 \\
\hline Competition & 3 & 4 & 5 & 6 \\
\hline Clustering & 1 & 5 & 5 & 6 \\
\hline Government; Indirect & 0.67 & 0.58 & 0.96 & $\mathbf{0 . 8 8}$ \\
\hline Research and development & 5 & 2 & 6 & 5 \\
\hline Extension activities & 4 & 3 & 6 & 5 \\
\hline Technology transfer & 4 & 4 & 5 & 6 \\
\hline Infrastructure & 3 & 5 & 6 & 5 \\
\hline Direct & 0.50 & 0.83 & 0.83 & 0.80 \\
\hline Economic policies & 5 & 5 & 6 & 5 \\
\hline Export incentives & 5 & 5 & 5 & 5 \\
\hline Exchange rate & 3 & 6 & 4 & 3 \\
\hline Trade zones & 1 & 6 & 5 & 5 \\
\hline Market protection & 1 & 3 & 5 & 6 \\
\hline OVERALL ASSESSMENT & .54 & .79 & .81 & .83 \\
\hline
\end{tabular}


Colombia has a significant competitive advantage over the other three countries in terms of the costs of labour, although there are indications that the increasing cost of labour is putting more pressure on growers to increase productivity. In Israel, labour costs are kept low by actively encouraging migrant workers and vacation labour. In Australia, the costs of labour are, by comparison, moderate. Conversely, labour costs in the Netherlands are the most expensive, which in part, has encouraged the Dutch to invest in mechanisation.

In the past, high inflation in both Israel and Colombia has made the cost of borrowing capital domestically prohibitive. Fortuitously, both countries have benefited from substantial foreign investments. For both Australia and the Netherlands, foreign investment is largely determined by the prevailing interest rates, which in part, is related to the current account balance and the stability of the currency in international money markets.

In terms of economic development, the Dutch flower export industry has achieved such economies of scale as to enable production and marketing to be fully integrated. Colombia and Israel have also achieved such economies of scale as to benefit from an investment in infrastructure. Both countries have constructed sophisticated post-harvest handling facilities at their major airports to accommodate the quantities of flowers shipped. In turn, the quantities of flowers shipped make it possible for both countries to contemplate chartering dedicated aircraft to transport flowers from Bogota (to Miami) and from Tel Aviv (to Cologne).

When Colombia and Israel first entered the world flower market, their comparative advantage, at least initially, was restricted to only one product. In the case of Colombia, standard carnations were the major flower export crop. For Israel, spray carnations provided the initial stimulus. However, declining prices and changing consumer demand encouraged both countries to significantly expand and improve the range and variety of flowers offered for sale. However, the means by which the expansion into "other flowers" has been achieved was somewhat different. In Colombia, the development of new flowers has been left almost entirely to the larger growers, who have mainly imported plant material from overseas for cultivation and evaluation under Colombian agro-ecological conditions. Research has focused primarily on enhancing yield and quality. In Israel, a far greater amount of cooperative research has been done in conjunction with the Government and producer groups to introduce and develop new flower crops. In the Netherlands, plant breeders are not only responding to the consumers demand for new flower types, but it could also be suggested that they create the demand.

In comparison to the quality of the flowers produced under the controlled greenhouse environments in the Netherlands, the flowers produced in both Colombia and Israel are of a somewhat lesser quality. The low cost, unsophisticated polyvinyl structures under which flowers are cultivated in Colombia and Israel, provide basic protection from the weather only. Crops are often exposed to significant diurnal variation in both temperature and humidity, which to varying degrees, not only adversely affect quality but also the ability to time crops for specific market days.

By comparison, the development of the flower export industry in Australia has been constrained by only a moderate investment in infrastructure, a limited range of product, poor quality control, insufficient freight space and poor distribution and marketing. This is reflected in the low score achieved for economic development. As the majority of properties are small and the quantity of flowers consigned to the international market is small, no significant economies of scale have yet been achieved. 
In Australia, the majority of flower export crops are grown outdoors with minimal protection. Furthermore, a large proportion of exports continue to be harvested from the bush where quality is highly variable. Whereas flower exports from both Colombia and Israel were based initially on some comparative advantage towards the production of an already well established commodity, the flower export industry in Australia has developed from the marketing of specialty products; at first, cymbidium orchids and then subsequently, from the cultivation and marketing of Australian wildflowers. This has created numerous problems for the flower export industry in both production and marketing. Furthermore, Australia has failed to establish a dedicated and cost competitive system for shipping perishable products to market.

In Australia, Colombia and Israel, the home market is not highly sophisticated, for consumers are generally immature and not quality conscious. Consequently, the rating given to all three countries was low. However, in the Netherlands where the domestic market is highly sophisticated, far greater demands are placed on the Dutch growers to produce only first grade flowers, for there are fewer opportunities to dispose of second grade product.

In terms of linkages between the flower export industry and allied or associated industries, there are few similarities between those crops grown for cut flowers and those cultivated as potted plants. In the Netherlands, the greenhouse construction technology and environmental management is directly transferable. In marketing, many of the auction markets also sell potted plants and the Dutch Flower Council, while they focus primarily on promoting fresh flowers, do not overlook the contribution that flowering plants and foliage make to the Dutch flower export industry. In both Colombia and Australia, the flower export industries stand very much alone and independent of other horticultural industries. In Israel, although there are some technological linkages between the flower industry and other horticultural industries, there are more powerful linkages in the marketing sector, for Agrexco is not only an exporter of flowers, but it also handles citrus, fruits and vegetables, many of which are also highly perishable.

The concentration of industry (clustering) seems to have had little impact on the development of the flower export industry in Australia. In Australia, the majority of cut flower enterprises are located within close proximity to the major metropolitan centres, but because of the size of the Australian continent, markets and points of despatch are geographically dispersed. There is no one central flower market in Australia where supply and demand might meet to establish price or quality and no one point for the aggregation of flower exports which might encourage some economies of scale. In Israel, the location of cut flower properties is dictated by the availability of water, suitable soils, a favourable aspect and proximity to either the airport or one of the thirteen regional transit stations. In Colombia, the concentration of cut flower enterprises in Bogota, Calais and Medellin, is due to the availability of air freight terminals. In the Netherlands, flower production is centred around two regional centres; the Westland and Aalsmeer.

In attempting to control inflation and to restrict the growth of the current account deficit, the Government of Australia has sought to maintain an artificially high exchange rate, much to the detriment of encouraging flower exports. However, of far greater consequence is the inability of Australian flower exports to access without impediment, the world's major markets. Unlike many of its competitors, Australia receives no preferential treatment into any of the overseas flower markets within which it trades.

With so few natural resources, the Dutch flower industry has been and remains dependent upon innovation in production and marketing to maintain its dominance in the international flower 
market. Agricultural policy has been instrumental in facilitating expansion, but more so through legislation, with reducing many of the encumbrances. Because of the highly sophisticated nature of technology and demand, several private companies are actively involved in research and development to breed more productive, better quality, better looking flowers which appeal more to the consumers changing demands. Despite the erosion of the Dutch share of the international flower market, sustained success is coming not so much from production as it is from the efficiency of the flower market and the distribution system. The Netherlands has an open policy of importing flowers from anywhere in the world, provided that such products make an interesting supplement to the normal range of flowers supplied, they are of good quality and can be supplied on a regular basis. Within the EU, cut flowers may move between countries duty free, but into the USA, Dutch flower growers receive no preferential treatment.

Much of the success that Israel has experienced in the international flower market can also be attributed to the strong focus Government gave to research and development. With the exception of a favourable climate, Israel has few natural advantages. Technology has been at the forefront in the development of efficient cultivation techniques because, for the majority of the flower crops cultivated, some modification to established cultural practices, selective breeding and the development of new flower crops have been important in establishing market leadership. The Government has also played a major role in creating the pre-requisite infrastructure on which the industry was developed. Through cash grants and new settlement allowances, the Government has encouraged new growers to enter the industry and for existing growers to expand.

\section{Conclusions}

While there is a vast difference between the value of Dutch flower exports (US\$2280 million) and the rest of the world, it is apparent that the basic factors of production are a great deal more important in the emergence of new flower export industries than the literature would suggest. The rate at which Colombian flower exports have grown from just US\$1.2 million in 1970 to their present day value of US\$555 million is indicative of the country's resource endowments rather than any selective factor disadvantage. Similarly, the rapid emergence of new flower export nations such as Ecuador and Zimbabwe can also be attributed to their resource endowments. Furthermore, while Dutch flower exports continue to dominate world trade (59\%), it is apparent that an increasing proportion of the flowers exported from the Netherlands are sourced from the developing countries (15\%) and re-exported, so that, in real terms, the Dutch flower growing industry is also losing market share.

In terms of the basic resource endowments, it would appear that land, water and climate are the most important variables, at least initially, in the evolution of a competitive flower export industry. While Porter (1990) would suggest that it is possible to modify the climate through constructing sophisticated greenhouses, with the recent advances in post-harvest handling and air freight (Ganitsky 1986), it is more cost effective to let nature provide the majority of inputs. Irrespective, without an appropriate investment in infrastructure, the opportunities available may never be realised. Land cannot substitute for capital even where its opportunity costs are zero (Root 1984). Its availability and accessibility is more often than not dependent upon technology and indirectly upon the investment of sufficient capital. Land only becomes a natural resource when society develops the need and ability to use it for production.

Similarly, at any point in time, the human resources within a nation will differ both in composition and quality. In the developing countries, agriculture traditionally makes the largest 
contribution to the gross domestic product and is the nations largest employer (80\%) (Timmer 1988). However, as economic development proceeds and productivity per worker increases, labour is released to work in other areas of the emerging economy, which, in turn, raises the cost of labour. Thus, in order to remain competitive, nations must seek to improve productivity per employee by raising product quality, adding more desirable product features, improving product technology or boosting production efficiency (Porter 1990).

In maintaining product quality, it is apparent that one of the most critical key success factors towards developing an internationally competitive flower export industry is to have complete control of the supply chain from the grower to the customer. Much of the success of both the Colombian and Israeli flower export industries can be attributed to the development of an integrated supply chain, the construction of appropriate post-harvest storage and processing facilities and the use of dedicated aircraft to move the product under ideal conditions. For the Netherlands, proximity to the majority of its customers in the EU enables Dutch flowers to be delivered by road under controlled conditions. Porter (1990) believes that for firms to be internationally competitive, they must sell through marketing channels that they control.

In developing these supply chain networks, several interrelated variables contribute to the evolution of successful flower export industries. In Colombia, Israel and the Netherlands, the concentration of flower production into small geographic areas (clustering), appears to have been important in facilitating the construction of the marketing and logistics infrastructure. The structure of the flower industry itself will either facilitate or constrain the development of flower exports. In the Netherlands, 92\% of all flowers move through the Dutch flower auctions, thus providing several points for consolidation and opportunities for flower exporters to enhance the product mix. The legislation under which Agrexco and the Flower Board in Israel was established was instrumental in the development of a central distribution facility at Ben Gurion airport (Tel Aviv). Ascolflores decision to construct a facility in Miami to receive Colombian flowers greatly facilitated the expansion of the flower export industry.

With the exception of Agrexco, government has had minimal direct involvement in the development of successful flower export industries. However, in most instances, appropriate fiscal policies have created a favourable environment for investment and government legislation has greatly facilitated the formation of strong, coordinated flower export councils, often providing them with the mechanisms to collect levies for research and development and generic promotion. In association with these flower export councils, government has played a pivotal role in facilitating the establishment and maintenance of product quality standards. It is abundantly clear that where these processes have remained under "voluntary" control, the flower export industry has failed to provide a cohesive and coordinated approach to either the development of flower export standards or new export markets.

However, where government has had a significant influence in facilitating the development of internationally competitive flower export industries is through negotiating preferential market access. As a member of the EU, Dutch flowers move freely within the European Union. Into the EU, Israel has successfully negotiated a duty free allowance of 17,000 tonnes of flowers per annum. Flowers from Zimbawe and other developing countries enter the EU duty free. Into the USA, Colombian flowers enter duty free. However, for a developed country such as Australia, import duties of $15-20 \%$ are payable on entry into the EU and $8 \%$ into the USA.

Rugman (1992) argues that because of the free trade agreement between Canada and the US, and the substantial investment by multinational companies in Canada, it is more appropriate for 
Canadian managers to view the US market as a domestic market, not an export market. This approach suggests that a Canadian manager needs to consider both the Canadian and the US diamond and to design strategies across both diamonds. To some extent, this approach may also have application in the world flower market. Not only is there a substantial US investment in Colombia, but there is also evidence of substantial Dutch investment in South Africa. As a consequence, these developing countries may already use their target market as a benchmark in their search for global competitive advantage. In the past, superior product quality has provided the Dutch flower export industry with a competitive advantage, but that leadership is rapidly diminishing as the new flower export nations achieve similar standards. However, there is a point beyond which further improvements in product quality will face diminishing marginal returns and rather than to add value, will only add cost. Unfortunately, this is likely to lead to a reduced consumer demand for flowers.

While Porter (1990) argues that firms gain competitive advantage where domestic markets are large and domestic consumers more sophisticated and demanding, it is highly doubtful that this proposition can be supported in the flower export industry. Japan is the most quality conscious flower market in the world, yet exports amount to less than $2 \%$ of production (RIRDC 1997b). In both Colombia and Israel, the domestic markets are relatively immature, yet these countries are respectively Number $2(10 \%)$ and Number $4(4 \%)$ in the world flower market. A firm's decision to export often arises in response to the firms desire to use spare production capacity or to dispose of obsolete products (Cavusgil and Godiwalla 1982), or where the firm has a differential advantage derived from the nature of its products, markets, technological orientation or resources (Cavusgil and Niven 1981). However, whether a firm ultimately pursues an export market will depend upon the strength of managerial aspirations for various business goals including growth, profit and market development; managements expectations about the effect of exporting on the business goals and the level of organisational commitment to the export market. Ganitsky (1989) suggests that the attitudes and behaviour of innate exporters are more conducive to eventual success than those of adoptive exporters. Van den Bosch and van Prooijen (1992) suggest that for a nation to be successful in the international market, it must first have an export orientation. Furthermore, the importing country must be receptive to the product from abroad which is often accompanied by habits, ideas and other aspects of a foreign culture which are new to them. Ford (1980) refers to this as distance and suggests that the closer the two countries are socially, culturally, geographically and technologically, the easier it is to do business. While Van den Bosch and van Prooijen (1992) conclude and agree with Porter (1990) that national culture works through the determinants of competitive advantage and is not in isolation to them, Thain (1990) believes that Porter pays inadequate attention to the human factor. In firms and nations, success results from individuals perceiving problems and opportunities and being motivated to plan and take whatever action is necessary to overcome the obstacles.

\section{References}

Aimone, T. 1998. Colombia's new air of optimism. Floraculture International. Vol 8(2). pp 18-23.

AIPH [International Professional Horticultural Federation]. 1996. Figures and Trends 1995.

Batt, P. J. 1982. Australia as a Market for New Zealand Cut Flowers and Foliage. Horticultural Market Research Unit. Report No 16. 
Batt, P. J. 1990. The Flower Market in Japan. Unpublished seminar paper to the Flower Export Forum. Australian National Flower Show. Melbourne.

Cavusgil, S.T. and J.R. Niven. 1981. Internal Determinants of Export Marketing Behaviour: An Empirical Investigation. Journal of Marketing Research. Vol 18. pp 114-119.

Cavusgil, S.T. and Y.M. Godiwalla. 1982. Decision Making for International Marketing: A Comparative Review. Management Decision. Vol 20(4). pp 47-54.

Central Bureau of Statistics. 1999. http://www.cbs.il/data

Colombia Today. 1990. The Colombian Economy. 1989. Vol 24(9). Colombia Information Service. New York.

Colombian Flowers. 1999. http://www.colombianflowers.com/4000/4041.htm

De Groot, N.S.P. 1998. Floriculture Worldwide. Trade and Consumption Patterns. World Conference on Horticultural Research. International Society for Horticultural Science. http://www.agrsci.unibo.it/wchr/wc1/degroot.html

Evans, H. D. 1989. Comparative Advantage and Growth. St Martins Press. New York.

Flower Council of Holland. 1991. Floriculture in the Netherlands.

Flower Council of Holland. 1998. Facts and Figures About the Dutch Horticulture Industry. http://www.bbh.nl/uk_bloem_feiten_98_link3.html

Flower Export Council of Australia. 1999. Industry Summary; A Snapshot of Australian Floriculture and Exports. http://www.iinet.net.au/ feca/industry.htm

Ford, D. 1980. The Development of Buyer-Seller Relationships in Industrial Markets. European Journal of Marketing. Vol 14 (5/6). pp 339-353.

Ganitsky, J. 1986. Strategic Lessons Emerging from the Performance of Colombia and Israel in International Flower Markets. Research in Domestic and International Agribusiness. Vol 6. pp 50-65.

Ganitsky, J. 1989. Strategies for innate and adoptive exporters; lessons from Israel's case. International Marketing Review. Vol 6(5). pp 50-65.

Hamrick, D. 1995. Israel feels competitive squeeze. Floraculture International. Vol 5(5). pp 20-23.

Hamrick, D. 1996. Dutch floriculture today; crisis or opportunity. Floraculture International. Vol 6(5). pp 14-20.

Holland Agriculture. 1989. Number 23. Informa.

Huszagh, S.M. and F.W. Huszagh. 1987. Understanding agricultural exports. International Marketing Review. Vol 4. Pp 16-30. 
Industry Commission. 1993. Horticulture. Report No. 29. Australian Government Publishing Service. Canberra.

Karmon, Y. 1971. Israel; A Regional Geography. Wiley Interscience.

Kohls, R.L. and J.N. Uhl. 1990. Marketing Agricultural Products. $7^{\text {th }}$ Edition. MacMillan.

Lanning, J. 1986. Selling Flowers and Plants to Europe. Austrade.

Lewis, S.R. 1988. Primary Exporting Countries in Chenery, H. and T. N. Srinivasan (ed). Handbook of Development Economics. North Holland.

Luxner, L. 1997. Colombia protest decertification. Floraculture International. Vol 7(6). pp 22-25.

Mentzer, J.T and A.C. Samli. 1981. A Model for Marketing in Economic Development. Columbia Journal of World Business. Vol 16. pp 91-101.

National Resource Centre in Floricultural Marketing. 1992. Unpublished report to industry. Curtin University of Technology.

Nichols, J.A.F., M. Lyn-Cook and S. Roslow. 1988. Strategies for Export Marketing of Non-Traditional Products. International Marketing Review. Vol 6(4). pp 58-71.

Offiongodon, A.M. 1988. Towards Improved Agricultural Products Marketing Strategy. European Journal of Marketing. Vol 22(6). pp 7-19.

Olentine, C. 1996. A key industry for Israel. Floraculture International. Vol 6(9). pp 57.

Pizano, M. 1995. Ecoflowers-Colombia develops environment-friendly flower growing. Floraculture International. Vol 5(6). pp 22-23.

Pizano, M. 1997. Colombia-three decades of progress. Floraculture International. Vol 7(6). pp 12-15.

Porter, M. E. 1980. Competitive Strategy: Techniques for Analysing Industries and Competitors. Free Press. New York.

Porter, M. E. 1990. The Competitive Advantage of Nations. Macmillan.

Poutsma, E., F.W. van Uxem, A.H.C.M. Walrens. 1987. Process Innovation and Automation in Small and Medium Sized Business. Deflt University Press.

Rabobank. 1992. A View of International Competitiveness in the Floristry Industry

RIRDC, 1997. The Australian Wildflower Industry. A Review-Second Edition. Rural Industries Research and Development Corporation. Report No. 97/64.

RIRDC. 1997a. A Study of the Netherlands Flower Market. Rural Industries Research and Development Corporation. Report No. 97/44. 31 pp. 
RIRDC. 1997b. A Study of the Japanese Flower Market. Rural Industries Research and Development Corporation. Report No. 97/41. 81 pp.

Root, F.R. 1984. International Trade and Investment. Fifth Edition. South Western.

Rugman, A.M. 1992. Porter Takes the Wrong Turn. Business Quarterly. Vol 56(3). pp 59-64.

Seringhaus, F.H.R. and P.J. Rosson. 1990. Government Export Promotion: A Global Perspective. Routledge.

Shepherd, G.S. and G.A. Futrell. 1982. Marketing Farm Produce. $7^{\text {th }}$ Edition. Iowa State University Press.

Thain, D.H. 1990. The War Without Bullets. Business Quarterly. Vol 54(1). pp 13-19.

Timmer, C. P. 1988. The Agricultural Transformation in Chenery, H. and T. N. Srinivasan (ed). Handbook of Development Economics. North Holland.

Van den Bosch, F.A.J. and A.A. van Prooijen. 1992. The Competitive Advantage of European Nations: The Impact of National Culture - a Missing Element in Porter's Analysis? European Management Journal. Vol 10(2). pp 173-177.

VBN. 1995. Statistiekboek. 1995. Vereniging van Bloemenveilingen Nederland.

Wain, J. 1992. Australian Flower Industry: Development of a Peak Industry Body. Working paper. Rural Industries Research and Development Corporation. 